\title{
ALAT PENGUKUR KECEPATAN DAN ARAH ANGIN YANG TERINTEGRASI MELALUI MIKROKONTROLER
}

\author{
Suyanto \\ Jurusan Teknik Elektro, Politeknik Negeri Bandung \\ email: suyanto_mas@yahoo.co.id
}

\begin{abstract}
Abstrak
Hembusan angin merupakan gabungan dari dua karakteristik angin yaitu kecepatan dan arah angin. Dua faktor ini sangat penting dalam pemanfaatan maupun pencegahan dampak hembusan angin. Alat pengukur kecepatan angin pada umumnya terpisah dengan alat pengukur arah angin. Komposisi kedua parameter angin tersebut dapat ditera melalui kombinasi Optocoupler dan kombinasi logik. Optocoupler akan membaca piringan kode dan menghasilkan keluaran berupa pulsa dan kombinasi logik. Lalu mikrokontroler AT89S52 akan mengolah data tersebut. Pulsa akan diolah agar menghasilkan keluaran kecepatan angin yang terjadi, sedangkan kombinasi logik akan diolah agar menghasilkan kemana arah angin sedang berhembus. Besarnya kecepatan angin dan arahnya ditampilkan pada LCD. Pengaturan kecepatan angin maksimum pada $11 \mathrm{~m} /$ det ditetapkan sebagai batas yang diperkenan. Kombinasi logik dengan tiga sensor mampu menghasilkan arah angin yang sesuai dengan kecepatannya.
\end{abstract}

Kata kunci : angin, pulsa dan kombinasi logik.

\section{PENDAHULUAN}

Anemometer adalah alat ukur kecepatan angin yang cukup akurat. Anemometer adalah alat yang digunakan untuk mengukur arah dan kecepatan angin. Satuan dari kecepatan angin yaitu knots atau $\mathrm{m} / \mathrm{s}$ dan arah angin dari $0^{\circ}-$ $360^{\circ}$. Tipe-tipe angin dan kekuatannya dapat ditentukan dengan menggunakan Skala Beaufort.

Tabel 1. Skala Beaufort ${ }^{[5]}$

\begin{tabular}{|c|c|c|c|}
\hline \multirow{2}{*}{ Skala } & \multicolumn{2}{|c|}{ Kecepatan Angin } & \multirow{2}{*}{ Kekuatan Angin } \\
\cline { 2 - 3 } & $\mathbf{m} / \mathbf{s}$ & $\mathbf{k m} / \mathbf{i a m}$ & angin reda \\
\hline 0 & $0.0-0.5$ & $0-1$ & sepoi - sepoi \\
\hline 1 & $0.6-1.7$ & $2-6$ & lemah \\
\hline 2 & $1.8-3.3$ & $7-12$ & sedang \\
\hline 3 & $3.4-5.2$ & $13-18$ & tegang \\
\hline 4 & $5.3-7.4$ & $19-26$ & keras \\
\hline 5 & $7.5-9.8$ & $27-35$ & keras sekali \\
\hline 6 & $9.9-12.4$ & $36-44$ & ribut \\
\hline 7 & $12.5-15.2$ & $45-54$ & ribut hebat \\
\hline 8 & $15.3-18.2$ & $55-65$ & badai \\
\hline 9 & $18.3-21.5$ & $66-77$ & taifun \\
\hline 10 & $21.6-25.1$ & $78-90$ & taifun hebat \\
\hline 11 & $25.2-29$ & $91-104$ & 105 keatas \\
\hline 12 & 29 keatas & & \\
\hline
\end{tabular}

Alat ukur digital yang dirancang adalah pengukur kecepatan angin dan arah angin dengan memanfaatkan teknologi Optocoupler dan Mikrokontroler AT89S52 dengan bantuan tampilan layar LCD. Alat ini dapat menampilkan besarnya kecepatan angin, menentukan arah angin, memberikan peringatan pada batas kecepatan angin dan arah angin ditampilkan menggunakan layar LCD. Optocoupler terdiri dari dua komponen yaitu LED dan photo transistor.

LED. LED (Light Emitting Diode) atau dioda pemancar cahaya adalah merupakan dioda semikonduktor sambungan PN yang akan memancarkan cahaya jika diberi prasikap maju. Pada dioda yang diberi prasikap maju, elektron pita konduksi melewati sambungan dan jatuh ke dalam hole. Pada saat elektronelektron jatuh dari pita konduksi ke pita valensi, maka akan memancarkan energi. Pada dioda penyearah, energi ini keluar sebagai panas. Tetapi pada LED, energi dipancarkan 
sebagai cahaya. Dengan menggunakan unsurunsur seperti Galium, Arsen dan Fosfor, pabrik dapat membuat LED yang memancarkan warna merah, kuning dan infra merah (tidak tampak).

Photo Transistor. Sebuah photo transistor adalah merupakan persambungan PN yang diberi prasikap mundur, dalam hal ini persambungan adalah sambungan basis kolektor dari transistor bipolar. Ketika persambungan diberi energi panas, maka arus bocor kolektor basis akan diperkuat. Keuntungan dari photo transistor adalah adanya penguatan arus dan menyebabkan photo transistor lebih peka daripada photo dioda, tetapi photo transistor mempunyai tanggapan waktu yang lebih lambat daripada photo dioda. Simbol skematik dari LED dan photo transistor dapat dilihat pada Gambar 1.

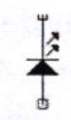

(a) Led

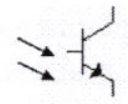

(b) Photo transistor

\section{Gambar 1. LED dan Photo Transistor}

Pengkondisi Sinyal. Pada umumnya keluaran sinyal listrik dari sensor atau transducer mempunyai besaran yang sangat kecil, sehingga untuk mengolahnya lebih lanjut diperlukan pengkondisian sinyal, dalam hal ini berupa suatu penguat. Penguat operasional (op-amp) merupakan komponen yang banyak dipakai karena mempunyai banyak keuntungan, misalnya mempunyai gain yang besar.

Mikrokontroler AT89S52. Mikrokontroler AT89S52 sering dipakai sebagai komponen pengendali pada suatu peralatan karena memiliki kelengkapan-kelengkapan yang diperlukan untuk bekerja dalam sistem single chip dan juga pertimbangan ekonomis ${ }^{[3]}$. Misalnya, mikrokontroler AT89S52 memiliki fitur 8 Kbyte downloadable flash memori, 3 level program memori lock, 256 byte RAM internal, 32 bit $\mathrm{I} / \mathrm{O}$ yang dapat digunakan semua, 3 buah timer/counter 16 bit, frekuensi kerja 0 - $33 \mathrm{MHz}$, tegangan operasi 4 Volt sampai 5,5 Volt.

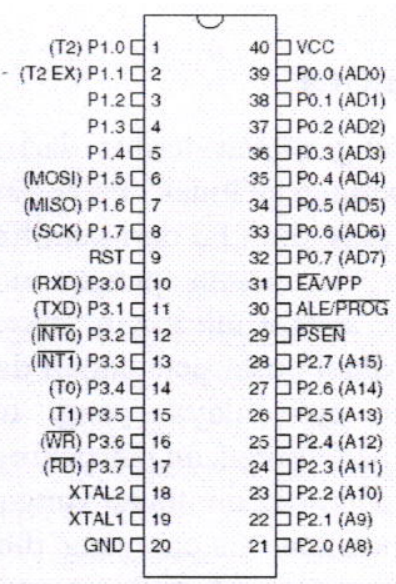

\section{Gambar 2. Konfigurasi Pin Mikrokontroler AT89S52}

Timer/Counter. Pada mikrokontroler MCS-51 terdapat dua buah timer/counter. Adanya timer/counter menambah fungsionalitas dari mikrokontroler ini. Dengan adanya timer/counter maka dapat digunakan, misalnya untuk menghitung kejadian (event), untuk menghasilkan Baud rate, atau untuk menghitung waktu.

Sebagaimana peralatan lain, pada mikrokontroler ini timer/counter juga diatur oleh special function register yaitu timer/counter kontrol (TCON alamat $88 \mathrm{~h}$ ), dan timer/counter mode kontrol (TMOD alamat $89 \mathrm{~h})$. Selain itu nilai byte bawah dan byte atas dari timer/counter disimpan dalam register TL dan $\mathrm{TH}$.

Jika difungsikan sebagai timer, maka akan menggunakan sistem clock sebagai sumber masukan pulsanya. Jika difungsikan sebagai counter (penghitung) maka akan menggunakan pulsa dari luar (eksternal) sebagai masukan pulsanya. Bahwa pada port 3 pada fungsi khususnya terdapat T0 (masukan luar untuk timer/counter 0) dan T1 (masukan luar untuk timer/counter 1). T0 berpadanan dengan port 3 pin 4 (P3.4) dan T1 berpadanan dengan port 3 pin 5 (P3.5).

Tabel 2. Bit Pemilih Mode Timber

\begin{tabular}{|c|c|c|c|}
\hline M1 & M0 & Timer mode & Keterangan \\
\hline 0 & 0 & 0 & 13 bit timer \\
\hline 0 & 1 & 1 & 16 bit timer \\
\hline 1 & 0 & 2 & 8 bit autoreload \\
\hline 1 & 1 & 3 & Split mode \\
\hline
\end{tabular}




\section{METODOLOGI}

Peralatan yang dibuat terdiri dari perangkat keras dan perangkat lunak. Pada perancangan perangkat keras, dimulai dari pemilihan sensor Optocoupler, kemudian pengkondisi sinyal, anemometer, sistem minimum mikrokontroler yang merupakan pusat pengendali dari seluruh sistem dan catu daya yang diperlukan. Sedangkan pada perancangan perangkat lunak ditekankan pada bagian utama yang digunakan untuk menjalankan sistem yang dibuat. Blok diagram dari sistem ditunjukkan pada Gambar 3.

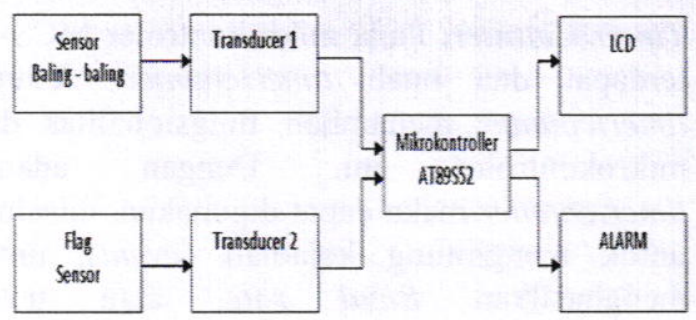

Gambar 3. Blok Diagram Sistem

Berdasarkan Gambar 3 dapat dijelaskan bahwa angin akan menggerakkan kedua buah sensor. Kemudian piringan kode yang menempel pada sensor akan dibaca oleh Optocoupler. Transducer pertama akan memberikan output pulsa yang akan dihitung oleh mikrokontroler dalam satuan waktu $(\mathrm{m} / \mathrm{s})$. Transducer 2 memberikan output berupa kombinasi logik yang diterjemahkan oleh mikro. Output dari mikrokontroler kemudian ditampilkan pada LCD. Yang ditampilkan pada LCD antara lain kecepatan dan arah angin. Apabila batas normalnya telah $11 \mathrm{~m} / \mathrm{s}$ maka alarm berbunyi.

Dalam perencanaan digunakan anemometer dan Optocoupler sebagai rangkaian sensor baling-baling. Output collector Optocoupler langsung dihubungkan ke opamp LM358 yang menggunakan mode inverting. Rangkaian sensor ditunjukkan pada Gambar 4.

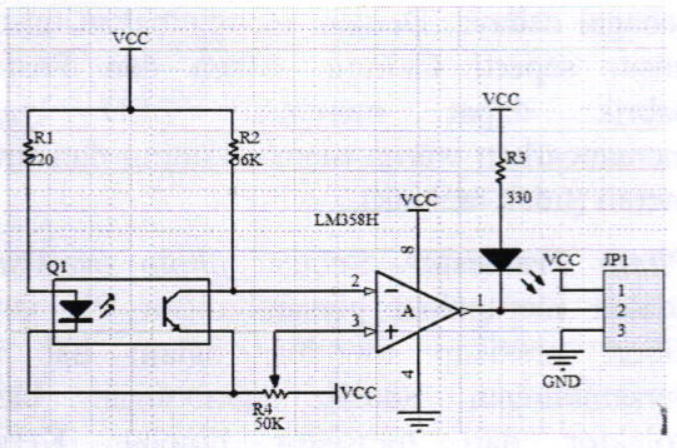

Gambar 4. Rangkaian Optocoupler dan Transducer

Mikrokontroler merupakan bagian yang sangat penting. Dalam perencanaan ini digunakan jenis AT89S52. Untuk sistem minimum mikrokontroler AT89S52 dipakai osilator dari kristal 11,0592 MHz dan 2 buah kapasitor 33 $\mathrm{pF}$ sedangkan rangkaian reset untuk menjaga agar pin RST mikrokontroler selalu berlogika rendah saat mengeksekusi program digunakan gabungan resistor dan kapasitor, seperti yang ditunjukkan pada Gambar 5. Pada kaki 11 IC AT89S52 dihubungkan dengan sebuah transistor yang berfungsi sebagai pengganti MAX232 agar level tegangan data serial dari mikrokontroler setara dengan level tegangan komunikasi port serial PC.

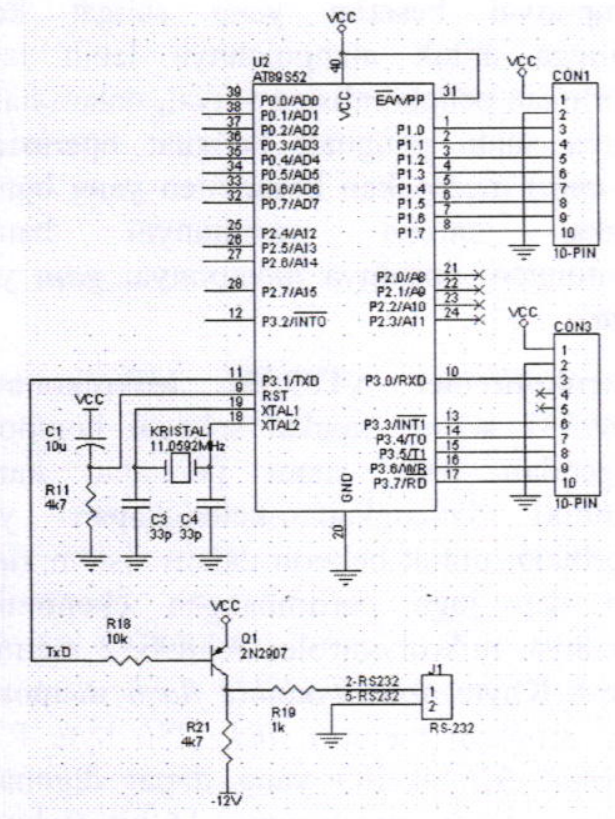

\section{Gambar 5. Rangkaian Mikrokontroler} AT89S52

Rangkaian keluaran ini terdiri dari rangkaian alarm dan rangkaian LCD, yang digunakan sebagai pemberi peringatan pada batas kecepatan maksimum. 


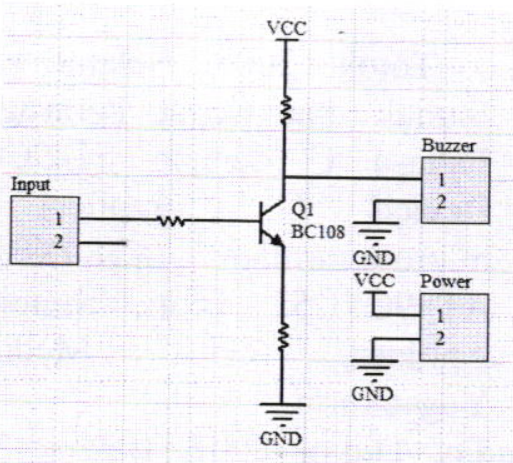

Gambar 6. Rangkaian Alarm

Untuk mikrokontroler keluarga MCS-51 bahasa tingkat tinggi yang dikembangkan antara lain Basic, Pascal, dan C. Bahasa C paling banyak dikembangkan ${ }^{[2]}$, sehingga pemrograman yang digunakan dalam perancangan ini juga menggunakan bahasa $\mathrm{C}$. Sedangkan untuk pemrograman Delphi digunakan Borland Delphi 7.

\section{HASIL DAN PEMBAHASAN}

Pengujian dilakukan terhadap dua keluaran pokok, yaitu keluaran Optocoupler dan tampilan pada LCD. Photo transistor akan aktif apabila diberi cahaya pada input basenya, sehingga ouput dari kolektornya tidak ada (berlogik "0"). Dan juga sebaliknya, apabila tidak ada cahaya pada input base-nya maka ouput collector berlogik "1". Hasil pengujian Optocoupler disajikan pada Tabel 3.

Tabel 3. Hasil Pengujian Optocoupler

\begin{tabular}{|c|c|c|c|c|}
\hline \multirow{2}{*}{ Opto } & \multicolumn{2}{|c|}{ Tanda Hitam } & \multicolumn{2}{c|}{ Tanda Putih } \\
\cline { 2 - 5 } & LED & Logik & LED & Logik \\
\hline 1 & ON & 0 & OFF & 1 \\
\hline 2 & ON & 0 & OFF & 1 \\
\hline 3 & ON & 0 & OFF & 1 \\
\hline 4 & ON & 0 & OFF & 1 \\
\hline
\end{tabular}

Pada saat berlogik "1" tegangan output collector sebesar $3.75 \mathrm{~V}$ dan saat berlogik "0" tegangannya sebesar $0.2 \mathrm{~V}$. Hasil tampilan LCD yang menunjukkan logik dari Optocoupler disajikan pada Tabel 4.
Tabel 4. Hasil tampilan LCD

\begin{tabular}{|c|c|c|c|}
\hline \multicolumn{3}{|c|}{ Output Logik dari } & \multirow{2}{*}{ Arah } \\
Optocoupler & \multirow{2}{*}{ Angin } \\
\cline { 1 - 2 } Sensor & Sensor & Sensor & \\
\hline $\mathbf{1}$ & $\mathbf{2}$ & $\mathbf{3}$ & \\
\hline 0 & 0 & 0 & Utara \\
\hline 0 & 0 & 1 & Timur laut \\
\hline 0 & 1 & 0 & Timur \\
\hline 0 & 1 & 1 & Tenggara \\
\hline 1 & 0 & 0 & Selatan \\
\hline 1 & 0 & 1 & Barat Daya \\
\hline 1 & 1 & 0 & Barat \\
\hline 1 & 1 & 1 & Barat Laut \\
\hline
\end{tabular}

Dari pengujian pada Tabel 4 didapatkan hasil pengukuran pulsa menggunakan frekuensi counter, yaitu sebesar $40.1 \mathrm{~Hz}$ dan pembacaan pada LCD sebesar $9 \mathrm{~m} / \mathrm{s}$.

Tabel 5. Perbandingan Alat dengan Anemometer

\begin{tabular}{|c|c|}
\hline Alat & $\begin{array}{c}\text { Anemometer } \\
\text { MAX 1043 Taiwan }\end{array}$ \\
\hline $1,25 \mathrm{~m} / \mathrm{s}$ & $1,5 \mathrm{~m} / \mathrm{s}$ \\
\hline $2,25 \mathrm{~m} / \mathrm{s}$ & $2,7 \mathrm{~m} / \mathrm{s}$ \\
\hline $2,75 \mathrm{~m} / \mathrm{s}$ & $3,2 \mathrm{~m} / \mathrm{s}$ \\
\hline
\end{tabular}

Optocoupler mendeteksi warna hitam dengan jarak 0,5 - 11,5 cm. Selain itu, didapatkan pengukuran kecepatan angin menggunakan frekuensi counter yaitu sebesar $40,1 \mathrm{~Hz}$ dan pembacaan pada LCD sebesar $9 \mathrm{~m} / \mathrm{s}$. Sehingga dapat dihitung hasil dari pengukuran kecepatan angin yaitu:

Pengukuran $=40.1 \times 22 \mathrm{~cm}=882.2 \mathrm{~cm} / \mathrm{s}=$ $8.82 \mathrm{~m} / \mathrm{s}$. Sehingga dapat dihitung eror sebesar:

$$
\text { Galat }=\frac{9-8.82}{9} \times 100 \%=2 \%
$$

Dari perbandingan yang terdapat pada Tabel 5. dapat dihitung kesalahan rata-rata yaitu sebesar $15.3 \%$. Kesalahan yang cukup besar ini dikarenakan konstruksi mekanik yang kurang sempurna dari piringan maupun casing. 


\section{KESIMPULAN}

1. Alat pengukur kecepatan dan arah angin ini berhasil direalisasikan dan bekerja dengan baik.

2. Hasil pengujian Optocoupler menunjukkan bahwa output kolektor berlogik " 0 " bila diberi cahaya dan berlogik " 1 " bila tidak ada cahaya.

3. Hasil tampilan LCD akan menunjukkan arah utara bila pada setiap sensor menunjukkan logik " 0 "

4. Dalam pembacaan arah angin tidak terdapat kesalahan, tetapi dalam pembacaan kecepatan angin rata-rata kesalahannya yaitu $15.3 \%$.

5. Alat ini memberi batas maksimum apabila kecepatan angin melewati $11 \mathrm{~m} / \mathrm{s}$.

\section{DAFTAR PUSTAKA}

Boylestad, Robert L. 1992. Electronic Device and Circuit Theory. Prentice Hall : New Jersey.
Budioko, Totok. 2005. Belajar Dengan Mudah dan Cepat Pemrograman Bahasa $\mathrm{C}$ dengan SDCC(Small Device C Compiler) pada mikrokontroller AT89X051 / AT89C51/52 Teori, Simulasidan Aplikasi. Gaus Media : Yogyakarta.

Wahyudin, Didin. 2007. Belajar Mudah Mikrokontroller AT89S52 Dengan Bahasa Basic Menggunakan Bascom8051. Andi : Yogyakarta.

Samantha, Olivia. Alat-alat Meteorologi 13 April 2008. http://2201oliv.blogspot.com/2008/04/alat-alat meteorologi.html

Wikipedia. Jenis-jenis Angin dan Tabel Skala Beaufort. 15 April 2008. http://wikipedia.org 